\title{
Avanços na pesquisa da raiva
}

\section{Advances in rabies research}

\author{
Pedro Manuel Leal Germano*
}

\begin{abstract}
GERMANO, P.M.L. Avan̨̧os na pesquisa da raiva. Rev. Saúde Pública, 28: 86-91, 1994. Fez-se revisão sobre os recentes avanços na pesquisa da raiva resultantes do progresso tecnológico das ciências biológicas, em especial a biologia molecular e a engenharia genética. Enfatizam-se os novos conhecimentos sobre as características e propriedades do víns rábico, sobre a patogenia e imunologia da infecęão, bem como o desenvolvimento de novas técnicas de diagnóstico e de avaliação de imunógenos. Destacam-se, na epidemiologia, a importância da identificação de cepas imunogenicamente distintas do vírus rábico, e na imunoprofilaxia, a produção de vacinas altamente imunogènicas.
\end{abstract}

Descritores: Raiva. Vírus da raiva, classificą̧ão. Vacina anti-rábica.

\section{Introdução}

Nas últimas décadas deste século, os avanços tecnológicos das ciências biológicas, notadamente a biologia molecular e a imunologia, permitiram aprofundar os conhecimentos sobre o vírus rábico, a patogenia e a imunoprofilaxia da infeç̧ão, assim como o desenvolvimento de métodos diagnósticos mais sensiveis e específicos.

O estabelecimento de novos conceitos sobre a epidemiologia da doença propiciou a aplicação de medidas de controle mais eficazes, principalmente nas áreas urbanas endêmicas.

Assim, com base nestes aspectos, constitui objetivo do presente trabalho fornecer novos elementos do estudo da raiva concernentes à sua história natural.

\section{A raiva no mundo}

Nos países industrializados da Europa e da América do Norte, a raiva silvestre representa a principal preocupação para as autoridades de saúde, estando a modalidade urbana controlada ou mesmo

\footnotetext{
* Departamento de Prática de Saúde Pública da Faculdade de Saúde Pública da Universidade de São Paulo - São Paulo, SP - Brasil

Separatas/Reprints: P.M.L.Germano - Av. Dr. Amaldo, 715 . 01246-904 - São Paulo, SP - Brasil

Ediçāo subvencionada pela FAPESP. Processo 94/0500-0
}

erradicada. Nessas circunstâncias, os riscos para a população humana diminuem consideravelmente. Nos países não industrializados da América Latina, Ásia e África, contudo, a raiva urbana é responsável, anualmente, por milhares de mortes, grande parte representada por crianças 5 . Na India, por exemplo, já se atingiu a cifra de 20.000 casos de raiva humana por ano, e na China, de aproximadamente $5.000^{48}$.

$\mathrm{Na}$ América Latina esse quadro não assume proporções tão graves, embora, anualmente sejam registrados inúmeros casos de raiva humana. No Brasil, particularmente, em 1991 foram registrados 65 óbitos humanos, porém, até novembro de 1992, já haviam sido diagnosticados 50 casos fatais ${ }^{11}$; destes, $76 \%$ (38 casos) só na região nordeste.

Dados revelam que 87 países, de um total de 167 pesquisados, mantêm reservatórios na população canina, os quais são responsáveis por $99 \%$ de todos os casos de raiva humana e mais de $90 \%$ de todos os tratamentos pós-exposição ${ }^{25}$. Estima-se que 2,7 bilhões de pessoas habitam regiões onde a raiva canina atinge mais de $5 \%$ da população, sendo que 5,4 milhões recebem tratamento pós-exposição anualmente ${ }^{27}$. No Brasil, no período de 1980 a 1991 , o cão foi responsável por $82,3 \%$ dos casos de raiva humana; 816 casos de origem canina de um total de $991^{*}$.

\footnotetext{
* Dados compilados de diferentes documentos de órgãos públicos federais, no citado periodo.
} 
$\mathrm{Na}$ América Latina devem ser acrescentados, ainda, os prejuizos anuais causados à pecuária pela raiva transmitida por morcegos hematófagos, especialmente aos rebanhos bovinos 5 . Deve-se ressaltar que o homem, também, pode vir a ser vitima fatal dos quirópteros. No Brasil, também no período de 1980 a 1991, os morcegos foram responsáveis por $5,2 \%$ dos casos de raiva humana; 52 casos de um total de $991^{*}$. Porém, $34,6 \%$ desses casos foram registrados apenas nos anos de 1990 e 1991 . Embora a raiva transmitida por quirópteros ainda seja problema maior para as zonas rurais e silváticas, constata-se nas zonas urbanas de grandes municipios brasileiros, tais como São Paulo e Brasilia, a presença de espécies insectívoras e frugivoras, expulsas de seus ecótopos naturais pela ação exploratória do homem, e atraidas pelas fontes de alimento presentes nesses centros. Do ponto de vista epidemiológico, os morcegos hematófagos constituem os reservatórios mais importantes para o virus da raiva, mas outras espécies de quirópteros são, também, passiveis de transmitir o agente.

\section{Classificação do virus}

A aplicação dos anticorpos monoclonais ao estudo da raiva possibilitou a classificação do vírus rábico dentro do gênero dos Lyssavirus com a identificação de 4 sorotipos: (1) o vírus rábico clássico, (2) o Lagos Bat Virus, (3) o Mokola, e (4) ○ Duvenhage . O sorotipo 1 pode ser isolado em quase todos os paises do globo, enquanto os 2,3 e 4 são encontrados no continente africano, embora o sorotipo 4 tenha sido isolado de morcegos frugivoros na Europa Central ${ }^{4}$, e hoje constitua uma preocupação das autoridades de saúde.

A ocorrência da cepa Duvenhage na Europa conduziu ao desenvolvimento de novas técnicas laboratoriais para diferenciar amostras contaminadas pelo vírus rábico das contaminadas pelos outros sorotipos, destacando-se o teste rápido de diagnóstico imunoenzimático para raiva (RREID - Rapid Rabies Enzyme ImmunoDiagnosis test) ${ }^{39}$.

* Dados compilados de diferentes documentos de órgāos públicos federais, no citado período

\section{Biologia Molecular}

Os avanços registrados em biologia molecular possibilitaram, em 1981, o relato da primeira seqüência dos genes do vírus rábico e estabeleceram as bases para a classificação definitiva do vírus mediante a análise antigênica comparativa ${ }^{51}$. Do mesmo modo, foi possível identificar a estrutura molecular e codificar o genoma viral, estabelecendo a correlação entre as seqüências do ácido nucléico primário e amino-ácidos e as propriedades biológicas e imunológicas do vírus rábico ${ }^{33,51}$.

Foi possível, também utilizando os recursos da biologia molecular ${ }^{8,14,18,43,51}$, determinar a extensão total do nucleotídeo dos genes estruturais, nucleoproteina $(\mathrm{N})$, fosfoproteína (NS), matriz protéica (M) e glicoproteina (G), e, em parte, da transcriptase (L), bem como descrever suas estruturas e funções; mapear e definir os sítios antigênicos; reconhecer as exigências estruturais necessárias para a atividade imunogênica; constatar as diferenças de qualidade entre antígeno solúvel e a glicoproteína inteira; identificar as regiões imunogênicas essenciais para a indução de anticorpos neutralizantes; e comprovar que fragmentos de peptídeos podem ser utilizados como determinantes antigênicos para linfócitos $\mathrm{B}$ e $\mathrm{T}$.

Assim, as pesquisas efetuadas com base na biologia molecular têm sido de relevante importância, não só para complementar os conhecimentos sobre a patogênese da infecção rábica e a imunologia, como também, para a determinação da variabilidade genética do vírus da raiva, inclusive entre cepas, e para o esclarecimento dos mecanismos de replicação e transmissão viral ${ }^{51}$.

\section{Patogenia}

Após a agressão, o vírus da raiva pode alcançar, diretamente, as terminações nervosas sensoriais e/ou motoras, ou permanecer algumas horas nas células musculares estriadas do tecido atingido, onde haverá um processo de amplificação viral, que propiciará a infecção dos nervos periféricos ${ }^{48}$. Pesquisa recente, porém, refere que a replicação viral continua no tecido muscular em estágios ulteriores da infecção ${ }^{45}$. O genoma viral é transportado no interior do axoplasma dos neurônios, centripeta- 
mente, à razão de 50 a $100 \mathrm{~mm}$ por dia, até alcançar o Sistema Nervoso Central (SNC) ${ }^{49}$.

Uma vez alcançado o SNC, o vírus atinge diferentes porções do cérebro e dissemina-se, centrifugamente, para todos os tecidos do hospedeiro $^{20}$. A virulência do vírus depende muito mais de sua integridade, do que propriamente do nivel de disseminação ou de distribuição topográfica da infeç̧ão ${ }^{25}$. Por outro lado, tem-se como certo que os sinais clínicos, tais como ataxia ou depressão, são conseqüência do efeito direto do virus na função das células neurais ${ }^{46}$. A infecção do sistema límbico, responsável pelo comportamento e, conseqüentemente, pela agressividade manifestada pelos hospedeiros durante a doença, bem como a infecção das glândulas salivares, através da qual há a eliminação de grande quantidade de vírus, são fatores fundamentais para a transmissão da raiva na natureza.

Estudos realizados com miotubos comprovam a replicação viral a esse nível e revelam que a junção neuro-muscular representa um local para o trânsito do vírus ${ }^{49}$. Glicosídeos e resíduos do ácido siálico estão relacionados com a fixação do vírus à membrana celular, assim como, gangliosídeos sializados e outros lipídeos participam desta adesão ${ }^{48}$.

Estudos mais detalhados sobre a patogenia são ainda necessários, no sentido de elucidar qual a forma que o vírus rábico adquire durante o período de incubação, e qual o papel especifico do tecido muscular, da junção neuro-muscular e dos nervos periféricos na progressão do vírus no organismo dos hospedeiros ${ }^{5}$. Esses aspectos assumem relevante importància, notadamente quando se observam casos de raiva humana com períodos de incubação longos, tais como os verificados nos EUA, com imigrantes provenientes do México (11 meses), do Laos (4 anos) e das Filipinas ( 6 anos), e, na Austrália, com imigrante procedente do Vietnan (6 anos e 4 meses) ${ }^{7,47}$.

\section{Imunoprofilaxia}

As contribuições fornecidas pela biologia molecular e pela engenharia genética possibilitaram a preparação de novos imunógenos, utilizando apenas pequenas porções da estrutura do vírus, determinados epítopos ou até fragmentos de peptí$\operatorname{deos}^{8,10,28,26,50}$.
Diferentes tipos de vacinas anti-rábicas de uso humano foram desenvolvidas ao longo dos últimos anos, o mesmo sucedendo para os imunógenos específicos para o controle da raiva animal. Os melhores resultados foram alcançados com as vacinas preparadas em culturas celulares, e dentre estas a de melhor qualidade é, até o momento, a preparada com células diplóides humanas $(\mathrm{CDH})$, embora não seja completamente isenta de riscos pós-vacinais $^{35,51}$. No entanto, a variação individual como resposta à vacina exige a avaliação, a intervalos regulares, da necessidade de boosters nos indivíduos em tratamento ${ }^{37}$. A vacina $\mathrm{CDH}$, porém, é de produção muito dispendiosa o que a torna, ainda, inviável nos tratamentos pós-exposição, em paises não industrializados, razão pela qual, por exemplo, na Tailândia $95 \%$ das pessoas que recebem tratamento anti-rábico, pós-exposição anualmente, são submetidas a vacinas derivadas de tecido nervoso ${ }^{50}$. Na Índia, a vacina tipo Semple, ainda é utilizada na rotina médica, apesar do número elevado de acidentes pós-vacinais ${ }^{3}$; de 39 pacientes com síndromes neuroparalíticos 3 tiveram exito letal ${ }^{49}$. Mesmo no Brasil, a base do tratamento anti-rábico, ainda consiste na aplicação de vacinas preparadas em cérebro de camundongos lactentes. Com base nesta problemática, tem-se tentado buscar outros substratos e novas técnicas de produção.

Estudos com vacinas anti-rábicas para humanos, preparadas em culturas de células de embrião de galinha, apresentaram elevado grau de eficácia e ausência de acidentes pós-vacinais graves ${ }^{1,6,36} . \mathrm{Na}$ China, uma vacina preparada em células primárias de rim de hamster, adicionada de adjuvante, está sendo utilizada em larga escala com relativo sucesso $^{32}$. A vantagem dessas vacinas, além de suas qualidades imunogênicas, é o baixo custo de produção.

Para os países não industrializados as vacinas anti-rábicas preparadas em culturas de células VERO parecem despontar como ideais para substituir as preparadas em tecido nervoso, sendo de tão boa qualidade quanto as $\mathrm{CDH}^{12,24,30,41}$.

Importantes são, também, as novas técnicas aplicadas ao controle de produção de vacinas antirábicas, no sentido de diminuir seus custos. Assim, já é possível determinar a potência in vitro de uma vacina, em substituição ao teste do National Institut of Health (NIH), utilizando a prova de ELISA com 
anticorpo monoclonal neutralizante anti-glicoproteína ${ }^{38}$, ou também, mediante a mensuração, via imunidade celular, da produção pelos linfócitos de interleucina-2 especifica ${ }^{26,39}$.

As perspectivas para o futuro, em matéria de imunógenos anti-rábicos, tanto para seres humanos, quanto para animais domésticos e silvestres, estão relacionadas com a produção de: vacinas recombinantes preparadas em culturas de células de insetos $^{17}$ (Psodoptera frugiperda), ou expressadas em baculovírus, poxvirus ou mesmo Escherichia coli; vacinas preparadas a partir da ribonucleproteína do vírus rábico ${ }^{30}$; vacinas preparadas com peptídeos sintéticos carreando epítopos para linfócitos B e $\mathrm{T}^{14}$; e a utilização de anticorpos monoclonais humanos especificos contra a glicoproteina e a nucleoproteína do virus da raiva no tratamento anti-rábico pós-exposição ${ }^{31}$.

Deve-se destacar, também, os progressos obtidos com a produção de vacinas anti-rábicas, de uso oral, para a imunização, não só de animais silvestres - raposas, lobos e skunks ${ }^{2,15}$, mas, também, para cães de áreas densamente povoadas, em substituição às campanhas de vacinação tradicionais ${ }^{16,29}$. $O$ sucesso desses imunógenos deve-se, principalmente, ao avanço verificado nas técnicas de engenharia genética, as quais possibilitaram o desenvolvimento de vacinas recombinantes eficazes e inócuas, até mesmo para outros vertebrados para os quais as vacinas não haviam sido destinadas originalmente, como, por exemplo, primatas ${ }^{42}$ e roedores 2.

\section{Epidemiologia}

A aplicação dos anticorpos monoclonais ao estudo da raiva possibilitou um grande avanço no conhecimento da epidemiologia da infeç̧ão, notadamente, no que concerne: a identificação das características dos padrōes antigênicos das diferentes cepas rábicas; a investigação de surtos epidêmicos; o reconhecimento de cepas endêmicas; a descoberta de fontes de infecção de casos isolados em áreas controladas ou livres de raiva; a diferenciação da raiva natural com aquela induzida por vacinas; e a diferenciação entre os diferentes sorotipos do vírus rábico.

Em todas as partes do mundo foram identificadas diferentes cepas do vírus da raiva na natureza.
No Brasil, em particular, foram isoladas e estudadas 6 cepas no Nordeste do país, nos Estados do Piauí, Rio Grande do Norte, Pernambuco e Alagoas, e duas outras no Sudeste, em São Paulo. Estas cepas foram isoladas de humanos, primatas, carnivoros, ruminantes e quirópteros ${ }^{19,22}$.

Deve-se destacar, contudo, que pesquisas realizadas com as vacinas anti-rábicas: ERA modificada e inativada, PV/BHK com adjuvante (hidróxido de alumínio ou avridine), CVS preparada em cérebro de camundongos lactentes, PV preparada em células NIHL, inativadas, protegeram, eficazmente, camundongos desafiados com as diferentes cepas brasileiras, quando aplicadas de acordo com os padrões da Organização Mundial da Saúde $\mathrm{e}^{13,21,23,40}$.

A técnica de PCR (Polymerase Chain Reaction) constitui, na atualidade, um método alternativo eficiente para estudos diagnósticos e epidemiológicos do vírus da raiva, permitindo identificar as diferenças entre cepas rábicas ${ }^{43}$. Os resultados obtidos com este método incentivam os chamados estudos de epidemiologia molecular, particularmente nos países nos quais têm sido relatadas falhas de vacinação ${ }^{44}$.

\section{Conclusões}

A pesquisa laboratorial em raiva teve nos últimos anos, especialmente no final da década de 80 , um avanço considerável. Destaca-se, principalmente, a evolução da qualidade das vacinas anti-rábicas, tanto as destinadas a seres humanos, quanto às espécies animais. $O$ aprimoramento das vacinas de uso humano possibilitou a drástica redução dos esquemas de tratamento pós-exposição. Contudo, a sorovacinação ainda continua sendo indicada nos casos de efraçōes cutâneas graves, principalmente, as próximas ao sistema nervoso central. A utilização de interferon, como substituto do soro-hiperimune heterólogo, ainda continua restrita, apesar dos estudos experimentais que comprovam as vantagens de sua aplicação ${ }^{34}$.

Embora muitas descobertas tenham sido feitas, graças aos conhecimentos advindos do desenvolvimento de outras ciências biológicas, parece distante ainda a solução para a cura da doença. Muitas questōes permanecem sem resposta, notadamente, 
as concernentes à patogenia da infecção e ao tipo de relação estabelecida entre o vírus e seus hospedeiros.

A raiva ainda é um problema imbativel em muitos lugares do mundo e um constante desafio para os pesquisadores, porém, um fato permanece claro, o de que a erradicação da raiva humana depende, fundamentalmente, do controle da raiva animal.

GERMANO, P.M.L. [Advances in rabies research]. Rev. Saúde Pública, 28: 86-91, 1994. Recent advances in research into rabies, based on the technological process of the biological sciences mainly molecular biology and genetic engineering, are mentioned. The current knowledge of the characteristics, properties pathogeny and immunology of the rabies views is presented, as well as the development of new diagnostic and vaccine evaluation techniques. The epidemiological importance of the identification of different immunogenic rabies virus strains and the role in immunoprophylaxis of the production of highly immunogenic vaccines, are set out.

Keywords: Rabies. Rabies virus, classification. Rabies vaccine.

\section{Referências Bibliográficas}

1. ARAI, Y.T.; OGATA, T.; OYA, A. Studies on Japanese-produced chick embryo cell culture rabies vaccines. Am. J. Trop. med. Hyg., 44:131-4, 1991.

2. ARTOIS, M.; GUITTRE, C.; THOMAS, I.; LEBLOIS, H.; BROCHIER, B.; BARRAT, J. Potencial pathogenicity for rodents of vaccines intended for oral vaccination against rabies: a comparison. Vaccine, 10:524-8, 1992.

3. ARYA, S.C. Acquisition of spongiform encephalopathies in India through sheep-brain, rabies vaccination. Indian $J$. Pediatr., 58:563-5, 1991.

4. ATANASIU, P. \& SUREAU, P. Rage. - In:Encyclopédie Médico Chirurgicale. Paris, Editions Techniques, 1987. v.7 $8065 \mathrm{C}^{10}$

5. BAER, G.M. Research toward rabies: prevention overview. Rev.Infect. Dis., 10:S575-80, 1988.

6. BARTH, R.; FRANKE, V.; MULLER, H.; WEINMANN, E. Purified chick-embryo-cell (PCEC) rabies vaccine: its potency performance in different test systems and in humans. Vaccine, 8:41-8, 1990.

7. BENMANSOUR, A.; LEBLOIS, H.; COULON, P; TUFFEREAU, C.; GAUDIN, Y.; FLAMAND, A.; LAFAY, F. Antigenicity of rabies virus glycoprotein. J. Virol., 65:4198-203, 1991.

8. BOURHY, H.; SUREAU, P.; TORDO, N. From rabies to rabies-related viruses. Vet. Microbiol. , 23:115-28, 1990.

9. BURGER, S.R.; REMALEY, A.T.; DANLEY, J.M.; MOORE, J.; MUSCHEL, R.J.; WUNNER, W.H.; SPITALNIK, S.L. Stable expression of rabies virus glycoprotein in Chinese harnster ovary cells. J. Gen. Virol., 72:359-67, 1991.
10. CONSALES, C.A.; MENDONCA, R.Z; GALLINA, N.M.; PEREIRA, C.A. Cytopathic effect induced by rabies virus in McCoy cells. J. Virol. Methods, 27:277-85, 1990.

11. CORDEIRO, C.F.; SILVA, E.V.; MIGUEL, O.; GERMANO, P.M.L. Avaliação da vacina anti-rábica ERA, frente a variantes antigênicas do virus da raiva, em diferentes periodos pós-imunização. Rev. Saúde Pública., 24:512-7, 1990.

12. DIETZSCHOLD, B. \& ERTL, H.C. New developments in the pre-and post-exposure treatment of rabies. Crit. Rev. Immunol., 10:427-39, 1991.

13. FEKADU, M.; SHADDOCK, J.H.; SUMNER, J.W; SANDERLIN, D.W.; KNIGHT, J.C.; ESPOSITO, J.J.; BAER, G.M. Oral vaccination of skunks with raccoon poxvirus recombinants expressing the rabies glycoprotein or the nucleoprotein. $J$. Wildl Dis, 27:681-4, 1991.

14. FRONTINI, M.G.; FISHBEIN, D.B.; GARZA RAMOS, J; FLORES COLLINS, E; BALDERAS TORRES, J.M.; QUIROZ HUERTA, G.; GAMEZ RODRIGUES. J.J.; BELOTTO, A.J.; DOBDINS, J.G.; LINHART, S.B. A field evaluation in Mexico of four baits for oral rabies vaccination of dogs. Am. J. Trop. Med. Hyg., 47:310-6, 1992.

15. FU, Z.F.; DIETZSCHOLD, B.; SCHUMACHER, C.L.; WUNNER, W.H.; ERTL, H.C.; KOPROWSKI, H. Rabies virus nucleoprotein expressed in and purified from insect cells is efficacious as a vaccine. Proc.Nall.Acad.Sci. U.S.A, 88:2001-5, 1991.

16. GAUDIN, Y.; TUFFEREAU, C.; SEGRETAIN, D.; KNOSSOW, M.; FLAMAND, A. Reversible conformational changes and fusion activity of rabies virus glycoprotein. $J$. Virol., 65:4853-9, 1991.

17. GERMANO, P.M.L.; SILVA, E.V.; SUREAU,P. Determinação de perfil antigènico de très cepas de vírus rábico isoladas no Brasil, através da técnica dos anticorpos monoclonais antinucleocapside. Rev. Fac. Med. Vet. Zootec. Univ. São Paulo, 25:199-205, 1988.

18. GERMANO, P.M.L.; MIGUEL, O.; ISHIZUKA, M.M.; SILVA, E.V. Avaliação de três cepas de vírus rábico antigenicamente distintas, em camundongos. II - Estudo da disseminação viral por diferentes órgãos. Rev. Saúde Pública, 22:473-8, 1988.

19. GERMANO, P.M.L.; SILVA, E.V.; CORDEIRO, C.F; PRETO, A.A. Vacina anti-rábica PV/BHK com avridine como adjuvante: avaliação da eficácia em camundongos. Arq. Biol. Tecnol. 33:865-78, 1990.

20. GERMANO, P.M.L.; SILVA, E.V.; MIGUEL, O.; SUREAU, P. Variantes antigénicas de la virus de rabia aisladas en el nordeste y sudeste del Brasil: estudio preliminar. Bol. Of. Sanit. Panam., 108:39-45, 1990.

21. GERMANO, P.M.L.; SILVA, E.V.; SILVA, E.V.; PRETO, A.A.; CORDEIRO, C.F. Avaliação em camundongos de vacinas anti-rábicas inativadas frente a variantes antigenicas do virus da raiva. Arq. Biol. Tecnol, 33:551-60, 1990.

22. HACIBEKTASOGLU, A.; INAL, A.; EYIGUN, C.; BARUT, A.; TURKAY, F.A. Comparison of PVRV and HDCV rabies vaccines as to immunity, reliability and protective value. Mikrobiyol. Bul., 26:26-36, 1992.

23. JACKSON, A.C. Biological basis of rabies virus neurovirulence in mice: comparative pathogenesis study using the immunoperoxidase technique. $J$. Virol., 65:537-40, 1991.

24. JOSHI, D.D. \& BOGEL, K. Role of lesser developed nations in rabies research. Rev. Infect. Dis., 10:S600-3, 1988.

25. KASEMPIMOLPORN, S.; HEMACHUDHA, T; KHAWPLOD, P; MANATSATHIT, S. Human immune response to rabies nucleocapsid and glycoprotein antigens. Clin. Exp. Immunol., 84:195-9, 1991. 
26. KHARMACHI, $H$; HADDAD, N.; MATTER, $H$. Tests of four baits for oral vaccination of dogs against rabies in Tunisia. Vet. Rec. 130:494, 1992.

27. KITALA, P.M.; LINDQVIST, K.J.; KOIMETT, E.; JOHNSON, B.K.; CHUNGE, C.N.; PERRIN, P.; OLSVIK, O. Comparison of human immune responses to purified Vero cell and human diploid cell rabies vaccines by using two different antibody titration methods. J. Clin. Microbiol., 28:1847-50, 1990.

28. LAFON, M.; EDELMAN, L.; BOUVET, J.P.; LAFAGE, M.; MONTCHATRE, E. Human monoclonal antibodies specific for the rabies virus glycoprotein and N protein.J. Gen. Virol., 71:1689-96, 1990

29. LIN, F.T. The protective effect of the large-scale use of PHKC rabies vaccine in humans in China. Bull. World Health Org., 68:449-54, 1990.

30. MANNEN., K.; HIRAMATSU, K.; MIFUNE, K.; SAKAMOTO, S. Conserved nucleotide sequence of rabies virus cDNA encoding the nucleoprotein. Virus Genes, 5:69-73, 1991.

31. MARCOVISTZ, R.; GERMANO, P.M.L.; RIVIERE, Y.; TSIANG, H.; HOVANESSIAN, H.G. The effect of interferon treatment in rabies prophylaxis in immunocompetent, immunosupressed and immunodeficient mice. J. Interferon Res., 7:17-27, 1987.

32. MOULIGNIER, A.; RICHER, A.; FRITZELL, C.; FOULON, D.; KHOUBESSERIAN, P.; DE RECONDO, J. Meningoradiculitis after injection of an antirabies vaccine: a vaccine from human diploid cell culture. Presse Med., 20:11213, 1991.

33. NATARAJAN, M.; MUKUNDAN, P.; JOHN, T.J. Immune response to purified chick embryo cell culture rabies vaccine manufactured in India. Indian J. Med. Res., 95:51-3, 1992.

34. OELOFSEN, M.J.; GERICKE, A.; JANSE VAN RENSBURG, M.N.; SMITH M.S. Imununity to rabies after administration of prophylactic human diploid-cell vaccine. $S$. Afr. Med J., 80:189-90, 1991.

35. PERRIN, P.; MORGEAUX, S.; SUREAU, P. In vitro rabies vaccine potency appraisal by ELISA: advantages of the immunocapture method with a neutralizing anti-glycoprotein monoclonal antibody. Biologicals, 18:321-30, 1990.

36. PERRIN, P.; GONTIER, C.; LECOCQ, E.; BOURHY, H. A modified rapid enzyme immunoassay for the detection of rabies and rabies-related viruses: RREID-lyssa. Biologicals, 20:51-8, 1992.

37. PHANUPHAK, P.; KHAOPLOD, P.; BENJAVONGKULCHAI, M.; CHUTIVONGSE, S.; WILDE, H. What happens if intradermal injections of rabies vaccine are partially or entirely injected subcutaneously? Bull. World Health Org., 68:83-5, 1990.

38. PRETO, A.A. \& GERMANO, P.M.L. Evaluation of the rabies vaccine, $\mathrm{PV} / \mathrm{BH} I \mathrm{~K}$ origin, against rabies virus strains of canine and bovine origin. Arq. Biol. Tecnol., 33:317-28, 1990.

39. RUPPRECHT, C.E.; HANLON, C.A.; CUMMINS, L.B.; KOPROWSKI, H. Primate responses to a vaccinia-rabies glycoprotein recombinant virus vaccine. Vaccine, 10:36874, 1992

40. SACRAMENTO, D.; BOURHY, H.; TORDO, N. PCR technique as an alternative method for diagnosis and molecular epidemiology of rabies virus. Mol. Cell Probes, 5:229-40, 1991.

41. SACRAMENTO, D.; BADRANE, H.; BOURHY, H.; TORDO, N. Molecular epidemiology of rabies virus in France: comparison with vaccine strains. J. Gen. Virol., 73(Pt 5):1149-58, 1992.

42. SHANKAR, V.; DIETZSCHOLD, B.; KOPROWSKI, H. Direct entry of rabies virus into the central nervous system without prior local replication. $J$. Virol., 65:2736-8, 1991.

43. SINCHAISRI, T.A.; NAGATA, T.; YOSHIKAWA, Y.; KAI, C.; YAMANOUCHI, K. Immunohistochemical and histopathological study of experimental rabies infection in mice. J. Vet. Med. Sci., 54:409-16, 1992.

44. STEELE, J.H. Rabies in the Americas and remarks on global aspects. Rev. Infect. Dis., 10:\$585-97, 1988.

45. SWAMY, H.S.; ANISYA, V.; NANDI, S.S.; KALIAPERUMAL, V.G. Neurological complications due to Sempletype antirabies vaccine: clinical and therapeutic aspects $J$. Assoc. Physicians India, 39:667-9, 1991.

46. TOLLIS, M.; DIETZSCHOLD, B.; VOLIA, C.B.; KOPROWSKI , $\mathrm{H}$. Immunization of monkeys with rabies ribonucleoprotein (RNP) confers protective immunity against rabies. Vaccine, 9:134-6, 1991.

47. TORNATORE, C.S. \& RICHERT, J.R. CNS demyelination associated with diploid cell rabies vaccine. Lancet, 335: $1346-7,1990$.

48. TSIANG, $H$. Rabies virus infection of myotubes and neurons as elements of the neuromuscular junction. Rev. Infect. Dis., 10:S733-8, 1988

49. TSIANG, H.; CECCALDI, P.E.; LYCKE, E. Rabies virus infection and transport in human sensory dorsal root ganglia neurons. J. Gen. Virol., 72:1191-4, 1991.

50. WILDE, H.; CHUTIVONGSE, S.; TEPSUMETHANON, W.; CHOOMKASIEN, P,; POLSUWAN, C.; LUMBERTDACHA, B. Rabies in Thailand: 1990. Rev. Infect. Dis., 13:644-52, 1991

51. WUNNER, W.H.; LARSON, J.K.; DIETZSCHOLD, B.; SMITH, C.L. The molecular biology of rabies viruses. Rev. Infect. Dis, 10:S771-84, 1988.

Recebido para publicaçāo em 24.6.1993 Aprovado para publicação em 28.10.1993 